\title{
Demographic factors associated with smoking cessation during pregnancy in New South Wales, Australia, 2000-2011
}

\author{
Erin Passmore ${ }^{1,2^{*}}$, Rhydwyn McGuire ${ }^{1}$, Patricia Correll ${ }^{1}$ and Jason Bentley ${ }^{1}$
}

\begin{abstract}
Background: Smoking during pregnancy increases the risk of adverse health outcomes for both the mother and the child. Rates of smoking during pregnancy, and rates of smoking cessation during pregnancy, vary between demographic groups. This study describes demographic factors associated with smoking cessation during pregnancy in New South Wales, Australia, and describes trends in smoking cessation in demographic subgroups over the period 2000 - 2011.
\end{abstract}

Methods: Data were obtained from the New South Wales Perinatal Data Collection, a population-based surveillance system covering all births in New South Wales. Multivariate logistic regression was used to explore associations between smoking cessation during pregnancy and demographic factors.

Results: Between 2000 and 2011, rates of smoking cessation in pregnancy increased from 4.0\% to 25.2\%. Demographic characteristics associated with lower rates of smoking cessation during pregnancy included being a teenage mother, being an Aboriginal person, and having a higher number of previous pregnancies.

Conclusions: Between 2000 and 2011, rates of smoking cessation during pregnancy increased dramatically across all demographic groups. However, specific demographic groups remain significantly less likely to quit smoking, suggesting a need for targeted efforts to promote smoking cessation in these groups.

Keywords: Smoking, Smoking cessation, Smoking in pregnancy, Epidemiology, Australia

\section{Background}

Smoking during pregnancy increases the risk of adverse outcomes for mother and infant. For the mother it is a major risk factor for ectopic pregnancy, premature rupture of the membranes, placental abruption, placenta praevia, spontaneous abortion, stillbirth, coronary heart disease, stroke, peripheral vascular disease, cancer and a variety of other diseases and conditions [1-4]. For the infant, maternal smoking contributes to an increased risk of being born at an earlier gestational age, lower birth weight, being born with congenital conditions [1-6], sudden infant death syndrome, as well as poorer health in early childhood [7-11].

In Australia, rates of smoking during pregnancy have declined over the last decade, from $19.0 \%$ in 2001 [12]

\footnotetext{
*Correspondence: epass@doh.health.nsw.gov.au

'NSW Ministry of Health, North Sydney, NSW, Australia

${ }^{2}$ School of Public Health and Community Medicine, University of New South

Wales, Sydney, NSW, Australia
}

to $13.2 \%$ in 2011 [13]. However, rates of smoking during pregnancy vary between demographic groups. Rates of smoking in pregnancy are elevated among teenage mothers, Aboriginal and Torres Strait Islander women, women who live outside major cities, and women of low socioeconomic status $[14,15]$. Moreover, within New South Wales, although rates of smoking in pregnancy have declined in all demographic groups, the largest decreases have been among the most socioeconomically advantaged groups, with a relatively smaller decline among women of ower socioeconomic status, Aboriginal women and women outside major cities, suggesting that inequalities in smoking in pregnancy have increased over time [14].

Relatively little data has been published on rates of smoking cessation during pregnancy in Australia. A Western Australian birth cohort study in 2002-03 found approximately $34 \%$ of women who smoked before pregnancy reported stopping smoking during pregnancy [16], while 
a New South Wales population-based study found that rates of smoking cessation during pregnancy declined from $4.5 \%$ in 1999 to $3.3 \%$ in 2003 [17]. However, like smoking during pregnancy, rates of smoking cessation during pregnancy also vary between demographic groups. Lu and colleagues reviewed nine cohort studies of smoking in pregnancy and found that the determinants of smoking cessation during pregnancy included maternal age, duration of smoking and number of cigarettes smoked per day, education level, socioeconomic status, and parity [18]. Similarly, a New South Wales study found that Aboriginal women, teenage mothers, women with previous children and women of lower socioeconomic status were less likely to stop smoking during pregnancy [17].

There is evidence for the effectiveness of interventions to support smoking cessation during pregnancy [19]. A recent systematic review concluded that smoking cessation interventions in pregnancy are effective in reducing the proportion of women who continue to smoke in late pregnancy, reducing the risk of low birth weight and preterm birth. There is also evidence that women consider provision of smoking cessation support during pregnancy to be appropriate [20-22]. However, success rates of smoking cessation interventions are often low, with interventions on average supporting an extra $6 \%$ of women to stop smoking during pregnancy, compared to usual care [19].

In order to develop successful maternal smoking cessation programs, the major determinants of smoking cessation during pregnancy need to be incorporated into intervention efforts, and interventions targeted towards women most at risk. Therefore, the aim of this study is to describe the demographic factors associated with smoking cessation during pregnancy in New South Wales, and to describe trends in smoking cessation in demographic subgroups over the period $2000-2011$.

\section{Methods}

\section{Study population and data source}

Birth data were obtained from the New South Wales Perinatal Data Collection, a population-based surveillance system covering all live births and stillbirths of at least 20 weeks gestation or, when gestational age is unknown, at least 400 grams birth weight in New South Wales. Data collection occurs via a form completed by the attending midwife or doctor. The form includes information on maternal characteristics, pregnancy, labour and delivery factors and infant outcomes. The Perinatal Data Collection is a statutory data collection under the New South Wales Public Health Act 2010. De-identified unit record data was accessed and analysed by the authors in their role as employees of the New South Wales Ministry of Health. The study population for estimating overall smoking rates included all mothers residing in New South
Wales who gave birth from 2000 to 2011, and for whom Aboriginality was recorded $(n=1,065,740)$. The study population for estimating smoking cessation was the subset of women who reported smoking in pregnancy $(n=147,961)$.

\section{Outcome measures}

Smoking status during pregnancy was obtained from the Perinatal Data Collection. The Perinatal Data Collection does not have a specific indicator of smoking cessation during pregnancy, therefore smoking cessation needs to be derived from indicators of smoking in the first and second half of pregnancy. For the period 2000 to 2010, the Perinatal Data Collection form asked two questions about smoking during pregnancy: "Did the mother smoke at all during the pregnancy?" and "Number of cigarettes smoked each day on average in the second half of pregnancy". Smoking cessation during pregnancy was defined as women who reported smoking during pregnancy, but reported smoking on average zero cigarettes per week in the second half of pregnancy. In 2011, the data collection form for the Perinatal Data Collection was revised to ask the following two questions about smoking behaviour: "Did the mother smoke at all during the first half of pregnancy?" and "Did the mother smoke at all during the second half of pregnancy?". Therefore in 2011 smoking was defined as smoking in either the first or second half of pregnancy, and smoking cessation was defined as smoking during the first half of the pregnancy but not smoking in the second half of the pregnancy.

\section{Covariates}

The following demographic characteristics were obtained from the Perinatal Data Collection: maternal age, whether antenatal care was received in the first 20 weeks, country of birth, self-reported Aboriginality of the mother, whether the birth was in a public or private hospital, parity, year of the birth, remoteness of residence and socioeconomic status. Remoteness was assigned based on the Accessibility/ Remoteness Index of Australia (ARIA+) [23] according to the Statistical Local Area (SLA) of residence. The Australian Bureau of Statistics Socioeconomic Index for Areas (SEIFA) Index of Education and Occupation [24] was used to create socioeconomic quintiles based on SLA of residence. Both SEIFA and ARIA+ were assigned on the basis of the 2006 census.

\section{Analysis}

Overall rates of smoking and smoking cessation were calculated for the whole study period in each of the above mentioned demographic groups. Multivariable logistic regression was carried out on the subset of women who reporting smoking during pregnancy to identify factors associated with smoking cessation. All analyses were performed using SAS 9.3. 


\section{Results}

\section{Smoking during pregnancy}

Of the 1,065,740 women who gave birth in New South Wales between 2000 and 2011, 147,961 (13.9\%) reported smoking during pregnancy. The proportion of women who smoked during pregnancy declined between 2000 and 2011, from 17.3\% in 2000 to $11.1 \%$ in 2011 (Figure 1). The demographic characteristics of women who smoked during pregnancy are presented in Table 1. The highest rates of smoking were among Aboriginal women (53.4\%), teenage mothers (38.9\%), and women with three or more previous pregnancies $(28.6 \%)$. The lowest rates of smoking in pregnancy were among private hospital patients $(2.2 \%)$ and women in the most socioeconomically advantaged quintile (3.7\%).

\section{Smoking cessation during pregnancy}

Of the 147,961 women who smoked during pregnancy in New South Wales between 2000 and 2011, 11,736 (7.9\%) reported stopping smoking during pregnancy. The rate of smoking cessation during pregnancy was stable between 2000 and 2006, but increased markedly from 2007 onward (Figure 2). The demographic groups most likely to smoke during pregnancy were also the least likely to stop smoking during pregnancy. The poorest rates of smoking cessation during pregnancy were among Aboriginal women (3.7\%) and women with three or more previous pregnancies (3.7\%). The highest rates of smoking cessation in pregnancy were among women in the most socioeconomically advantaged quintile (16.7\%), women born overseas (14.9\%) and women who gave birth in private hospitals (14.2\%).

In multivariable logistic regression analyses (Table 2), after adjusting for all other demographic characteristics, the strongest independent predictor of rates of smoking cessation in pregnancy was the year in which the baby was born, with the odds of smoking cessation increasing in each two year period between 2000-2001 and 2010-11.
After adjusting for covariates, the odds of smoking cessation were higher among the following demographic groups: women who had their first antenatal care visit before 20 weeks gestation, women who gave birth in private hospitals, non-Aboriginal women, women with higher maternal age, women with fewer previous pregnancies, and women living in major cities.

\section{Demographic factors associated with smoking cessation during pregnancy - a comparison of 2000 and 2011}

Comparing the two years 2000 and 2011, the rates of smoking cessation in pregnancy improved in all demographic groups (Table 3). However, most risk factors for continuing to smoke throughout pregnancy in 2000 remained risk factors in 2011. The notable exception was women who gave birth in public hospitals: in 2000, women who gave birth in public hospitals were less likely to stop smoking during pregnancy than women who gave birth in private hospitals, however in 2011 the reverse was true. The groups with the poorest rates of smoking cessation - Aboriginal women, and women with three or more previous pregnancies - remained the same in both time periods. The greatest absolute increase in cessation rates was in the two most advantaged socioeconomic quintiles and in women born overseas. The least improvement in cessation rates was among Aboriginal women, women giving birth in private hospitals, and teenage mothers.

\section{Discussion}

This study examined demographic characteristics associated with smoking cessation in pregnancy and trends in these demographic characteristics between 2000 and 2011. Demographic characteristics associated with both higher rates of smoking in pregnancy and lower rates of smoking cessation during pregnancy included being a teenage mother, living outside major cities, being an Aboriginal person, and having an increasing number of

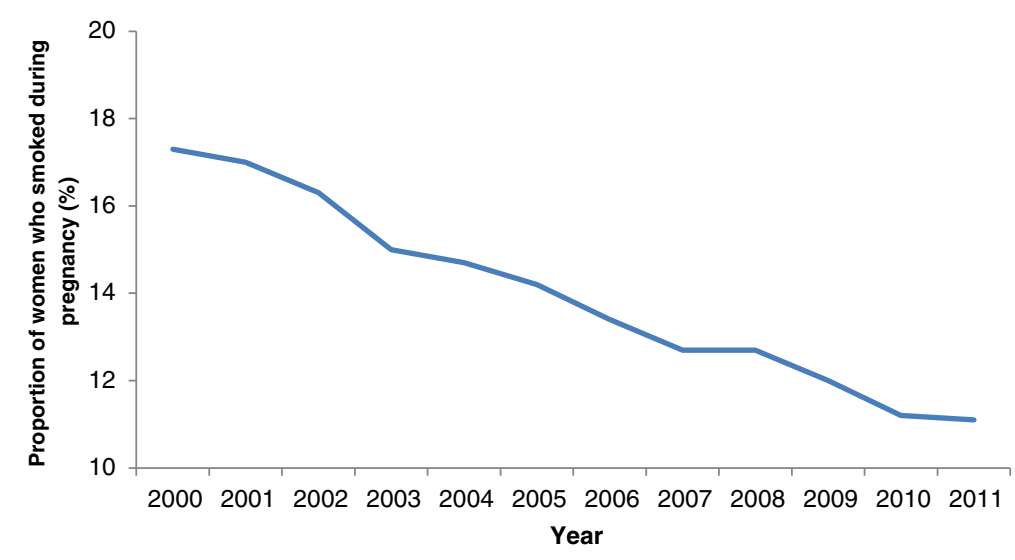

Figure 1 Proportion of women who smoked during pregnancy, New South Wales, 2000-2011. 
Table 1 Rates of smoking and smoking cessation during pregnancy, New South Wales, 2000-2011

\begin{tabular}{|c|c|c|c|c|c|}
\hline \multirow{2}{*}{ Demographic characteristic } & & \multicolumn{2}{|c|}{ Smoked at all during pregnancy } & \multicolumn{2}{|c|}{ Ceased smoking during pregnancy } \\
\hline & & $\bar{N}$ & \%* & $\mathrm{N}$ & $\% * *$ \\
\hline \multirow[t]{2}{*}{ Hospital type } & Public & 142,431 & 17.6 & 10,949 & 7.7 \\
\hline & Private & 5,530 & 2.2 & 787 & 14.2 \\
\hline \multirow[t]{5}{*}{ SEIFA quintile (Education/Occupation) } & 1st (most advantaged) & 7,667 & 3.7 & 1,282 & 16.7 \\
\hline & 2nd & 19,884 & 9.4 & 1,856 & 9.3 \\
\hline & $3 r d$ & 30,939 & 14.1 & 2,477 & 8.0 \\
\hline & 4th & 37,182 & 18.5 & 2,843 & 7.6 \\
\hline & 5th (most disadvantaged) & 52,246 & 22.9 & 3,277 & 6.3 \\
\hline \multirow[t]{3}{*}{ Country of birth and Aboriginality } & Australian born non-Aboriginal & 114,007 & 15.8 & 8,501 & 7.5 \\
\hline & Aboriginal & 16,198 & 53.4 & 593 & 3.7 \\
\hline & Non Australian born & 17,756 & 5.7 & 2,642 & 14.9 \\
\hline \multirow[t]{3}{*}{ Maternal age (years) } & $<20$ & 15,841 & 38.9 & 937 & 5.9 \\
\hline & $20-34$ & 111,803 & 14.0 & 8,863 & 7.9 \\
\hline & $35+$ & 20,317 & 8.9 & 1,936 & 9.5 \\
\hline \multirow[t]{4}{*}{ Number of previous pregnancies } & 0 & 51,250 & 11.5 & 6,777 & 13.2 \\
\hline & 1 & 41,436 & 11.6 & 2,550 & 6.2 \\
\hline & 2 & 27,076 & 16.8 & 1,361 & 5.0 \\
\hline & $3+$ & 28,080 & 28.6 & 1,044 & 3.7 \\
\hline \multirow[t]{2}{*}{ Remoteness (ARIA+) } & Major city & 73,685 & 10.2 & 7,583 & 10.3 \\
\hline & Non major city & 74,233 & 21.5 & 4,152 & 5.6 \\
\hline \multirow{2}{*}{$\begin{array}{l}\text { Duration of pregnancy at first } \\
\text { antenatal care visit }\end{array}$} & Less than 20 weeks & 117,672 & 12.4 & 9,979 & 8.5 \\
\hline & $20+$ weeks & 26,912 & 25.1 & 1,528 & 5.7 \\
\hline Total & & 147,961 & 13.9 & 11,736 & 7.9 \\
\hline
\end{tabular}

*Denominator: all women who gave birth **Denominator: women who smoked at all during pregnancy.

previous pregnancies. These associations were observed in the first and last year of the study period. The study findings are consistent with previous findings from Australia [16,17] and internationally [18] that rates of smoking cessation during pregnancy are lower among teenage mothers, Aboriginal women, and women with more children.

This study indicates that smoking during pregnancy decreased steadily between 2000 and 2011, and smoking cessation during pregnancy was stable between 2000 and 2006 but increased markedly from 2007 onward. Many factors may have contributed to the changes in smoking behaviour observed in this study. At the population level, the adult smoking rate in NSW has been declining for over 30 years [25]. This decline is likely a result of sustained tobacco control strategies including taxation, advertising bans, mass media campaigns, and smoke-free environment legislation [26]. Recent initiatives include increases in the tobacco excise in 2010 and 2013, the introduction of bans on point-of-sale tobacco product displays in 2011, and the introduction of plain packaging of tobacco products in 2012 [26]. These population-level initiatives are likely to have raised general awareness of the risks of smoking among pregnant women, and contributed to the decline in smoking in pregnancy and increase in cessation during pregnancy observed in this study. However, the reason for the marked increase in rates of smoking cessation during pregnancy since 2007 is unclear. Although antenatal care providers are likely to provide some smoking cessation support as part of routine care, to the authors' knowledge there have been no specific interventions targeting smoking in pregnancy, or changes in antenatal care practices since 2007, that would explain the sudden marked increase in cessation.

Despite the overall decline in smoking during pregnancy, demographic disparities in rates of smoking and smoking cessation in pregnancy remain substantial. Demographic groups including Aboriginal women, teenage mothers, women living outside major cities and women with three or more previous pregnancies remain significantly less likely to quit smoking during pregnancy. Moreover, although smoking cessation during pregnancy has increased in all demographic subgroups since 2000, the improvement in smoking cessation in these demographic 
Table 2 Demographic factors associated with smoking cessation during pregnancy, New South Wales, 2001-2011

\begin{tabular}{|c|c|c|c|c|}
\hline Demographic characteristic & & Adjusted odds ratio & 95\% Confidence interval & $P$-value \\
\hline \multirow[t]{6}{*}{ Year of birth } & $2000-2001$ & Reference category & & $<0.001$ \\
\hline & $2002-2003$ & 1.00 & {$[0.91,1.09]$} & \\
\hline & 2004-2005 & 1.07 & {$[0.93,1.24]$} & \\
\hline & $2006-2007$ & 1.28 & {$[1.05,1.57]$} & \\
\hline & 2008-2009 & 3.37 & {$[2.51,4.52]$} & \\
\hline & 2010-2011 & 6.91 & {$[5.50,8.69]$} & \\
\hline \multirow[t]{2}{*}{ Duration of pregnancy at first antenatal visit } & $<20$ weeks & Reference category & & $<0.001$ \\
\hline & $20+$ weeks & 0.79 & {$[0.73,0.85]$} & \\
\hline \multirow[t]{2}{*}{ Hospital type } & Public & Reference category & & $<0.001$ \\
\hline & Private & 1.61 & {$[1.29,2.01]$} & \\
\hline \multirow[t]{5}{*}{ SEIFA quintile (Education/Occupation) } & 1st (most advantaged) & 1.70 & {$[1.04,2.79]$} & \\
\hline & 2nd & 1.07 & {$[0.62,1.82]$} & \\
\hline & $3 r d$ & 1.34 & {$[0.80,2.23]$} & \\
\hline & 4th & 1.01 & {$[0.61,1.68]$} & \\
\hline & 5th (most disadvantaged) & Reference category & & 0.116 \\
\hline \multirow[t]{3}{*}{ Country of birth and Aboriginality } & Australian born non-Aboriginal & Reference category & & $<0.001$ \\
\hline & Aboriginal & 0.55 & {$[0.50,0.61]$} & \\
\hline & Non Australian born & 1.60 & {$[1.44,1.78]$} & \\
\hline \multirow[t]{3}{*}{ Maternal age (years) } & $<20$ & 0.53 & {$[0.44,0.64]$} & \\
\hline & $20-34$ & 0.87 & {$[0.77,1.00]$} & \\
\hline & $35+$ & Reference category & & $<0.001$ \\
\hline \multirow[t]{4}{*}{ Number of previous pregnancies } & 0 & Reference category & & $<0.001$ \\
\hline & 1 & 0.45 & {$[0.41,0.49]$} & \\
\hline & 2 & 0.36 & {$[0.32,0.39]$} & \\
\hline & $3+$ & 0.27 & {$[0.24,0.30]$} & \\
\hline \multirow[t]{2}{*}{ Remoteness (ARIA+) } & Major city & Reference category & & $<0.001$ \\
\hline & Non-major city & 0.44 & {$[0.31,0.62]$} & \\
\hline
\end{tabular}

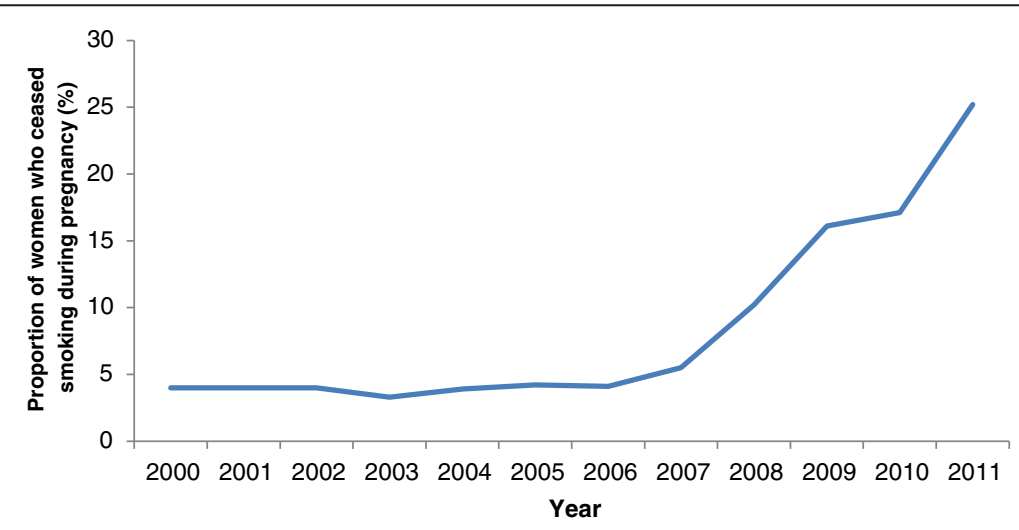

Figure 2 Proportion of women who ceased smoking during pregnancy*, New South Wales, 2000-2011. *Denominator: Women who smoked during pregnancy. 
Table 3 Rates of smoking cessation during pregnancy by demographic factors, New South Wales, 2000 and 2011

\begin{tabular}{|c|c|c|c|c|c|c|c|c|c|c|}
\hline \multicolumn{2}{|l|}{ Demographic characteristic } & \multicolumn{4}{|c|}{ Rates of smoking cessation during pregnancy } & \multirow{3}{*}{$\begin{array}{l}\text { Absolute increase in smoking } \\
\text { cessation rate, } 2000 \text { to } 2011\end{array}$} & \multicolumn{4}{|c|}{ Multivariable logistic regression } \\
\hline & & \multicolumn{2}{|l|}{2000} & \multicolumn{2}{|l|}{2011} & & \multicolumn{2}{|l|}{2000} & \multicolumn{2}{|l|}{2011} \\
\hline & & $\begin{array}{l}\text { No. of } \\
\text { women } \\
\text { who quit }\end{array}$ & $\begin{array}{l}\text { \% of } \\
\text { smokers } \\
\text { who quit }\end{array}$ & $\begin{array}{l}\text { No. of } \\
\text { women } \\
\text { who quit }\end{array}$ & $\begin{array}{l}\% \text { of } \\
\text { smokers } \\
\text { who quit }\end{array}$ & & $\begin{array}{l}\text { Adjusted } \\
\text { odds ratio }\end{array}$ & $\begin{array}{l}95 \% \\
\text { Confidence } \\
\text { Interval }\end{array}$ & $\begin{array}{l}\text { Adjusted } \\
\text { odds ratio }\end{array}$ & $\begin{array}{l}\text { 95\% Confidence } \\
\text { Interval }\end{array}$ \\
\hline \multirow[t]{2}{*}{ Hospital type } & Public & 530 & 3.8 & 2,607 & 25.2 & 21.4 & \multicolumn{2}{|c|}{ Reference category } & \multicolumn{2}{|c|}{ Reference category } \\
\hline & Private & 66 & 10.6 & 45 & 20.9 & 10.3 & 2.0 & {$[1.1,3.6]$} & 0.4 & {$[0.2,0.5]$} \\
\hline \multirow[t]{5}{*}{$\begin{array}{l}\text { SEIFA quintile (Education } \\
\text { /Occupation) }\end{array}$} & $\begin{array}{l}\text { 1st (most } \\
\text { advantaged) }\end{array}$ & 69 & 6.8 & 201 & 43.0 & 36.2 & 1.2 & {$[0.5,2.7]$} & 2.1 & {$[1.6,2.8]$} \\
\hline & 2nd & 145 & 6.0 & 413 & 33.3 & 27.3 & 1.2 & {$[0.6,2.6]$} & 1.6 & {$[1.2,2.1]$} \\
\hline & $3 r d$ & 81 & 2.9 & 602 & 27.4 & 24.5 & 0.9 & {$[0.5,1.5]$} & 1.3 & {$[1.0,1.6]$} \\
\hline & 4th & 106 & 3.7 & 633 & 21.1 & 17.4 & 1.3 & {$[0.8,2.0]$} & 1.0 & {$[0.8,1.3]$} \\
\hline & $\begin{array}{l}\text { 5th (most } \\
\text { disadvantaged) }\end{array}$ & 195 & 3.5 & 803 & 22.1 & 18.6 & \multicolumn{2}{|c|}{ Reference category } & \multicolumn{2}{|c|}{ Reference category } \\
\hline \multirow[t]{3}{*}{$\begin{array}{l}\text { Country of birth and } \\
\text { Aboriginality }\end{array}$} & $\begin{array}{l}\text { Australian born } \\
\text { non-Aboriginal }\end{array}$ & 498 & 4.3 & 1,949 & 25.0 & 20.7 & \multicolumn{2}{|c|}{ Reference category } & \multicolumn{2}{|c|}{ Reference category } \\
\hline & Aboriginal & 16 & 1.4 & 212 & 13.7 & 12.3 & 0.5 & {$[0.3,0.8]$} & 0.6 & {$[0.5,0.7]$} \\
\hline & $\begin{array}{l}\text { Non Australian } \\
\text { born }\end{array}$ & 82 & 4.3 & 491 & 40.3 & 36.0 & 1.1 & {$[0.9,1.4]$} & 1.6 & {$[1.4,1.9]$} \\
\hline \multirow[t]{3}{*}{ Maternal age (years) } & $<20$ & 82 & 5.0 & 197 & 19.8 & 14.8 & 1.1 & {$[0.8,1.6]$} & 0.7 & {$[0.5,0.8]$} \\
\hline & $20-34$ & 453 & 4.0 & 2,028 & 25.4 & 21.4 & 1.1 & {$[0.8,1.4]$} & 0.9 & {$[0.8,1.1]$} \\
\hline & $35+$ & 61 & 3.4 & 427 & 27.1 & 23.7 & \multicolumn{2}{|c|}{ Reference category } & \multicolumn{2}{|c|}{ Reference category } \\
\hline \multirow{4}{*}{$\begin{array}{l}\text { Number of previous } \\
\text { pregnancies }\end{array}$} & 0 & 347 & 6.8 & 1,017 & 29.9 & 23.1 & \multicolumn{2}{|c|}{ Reference category } & \multicolumn{2}{|c|}{ Reference category } \\
\hline & 1 & 150 & 3.3 & 748 & 26.5 & 23.2 & 0.5 & {$[0.4,0.6]$} & 0.8 & {$[0.7,0.9]$} \\
\hline & 2 & 55 & 2.1 & 480 & 23.8 & 21.7 & 0.3 & {$[0.2,0.4]$} & 0.7 & {$[0.6,0.8]$} \\
\hline & $3+$ & 44 & 1.8 & 407 & 17.8 & 16.0 & 0.3 & {$[0.2,0.5]$} & 0.5 & {$[0.4,0.6]$} \\
\hline \multirow[t]{2}{*}{ Remoteness (ARIA+) } & Major city & 392 & 4.8 & 1,523 & 31.1 & 26.3 & \multicolumn{2}{|c|}{ Reference category } & \multicolumn{2}{|c|}{ Reference category } \\
\hline & Non major city & 204 & 3.1 & 1,129 & 20.0 & 16.9 & 0.8 & {$[0.5,1.3]$} & 0.7 & {$[0.6,0.9]$} \\
\hline \multirow[t]{2}{*}{$\begin{array}{l}\text { Duration of pregnancy at } \\
\text { first antenatal care visit }\end{array}$} & $\begin{array}{l}\text { Less than } \\
20 \text { weeks }\end{array}$ & 519 & 4.6 & 2,198 & 26.4 & 21.8 & \multicolumn{2}{|c|}{ Reference category } & \multicolumn{2}{|c|}{ Reference category } \\
\hline & $20+$ weeks & 75 & 2.5 & 428 & 21.2 & 18.7 & 0.6 & {$[0.5,0.8]$} & 0.8 & {$[0.7,0.9]$} \\
\hline TOTAL & & 596 & 4.0 & 2,652 & 25.2 & 21.2 & N/A & & & \\
\hline
\end{tabular}


groups is less than in other groups. To address these inequities, future efforts to reduce smoking in pregnancy may need to target specific population groups. Ongoing monitoring and evaluation is also valuable to assess the effectiveness of smoking cessation interventions in specific population groups, and the impact on pregnancy and birth outcomes.

Of particular concern are the high rates of smoking and low rates of smoking cessation among Aboriginal women. Aboriginal women continue to have the highest rates of smoking and lowest rates of smoking cessation during pregnancy of any demographic group, and the gap between Aboriginal and non-Aboriginal women is substantial. Reducing rates of smoking during pregnancy among Aboriginal women, and closing the gap in rates of smoking in pregnancy between Aboriginal and nonAboriginal women, are key priorities in New South Wales [27]. The New South Wales Government state plan for the period 2011-2021 sets targets to reduce rates of smoking in pregnancy by $0.5 \%$ per year for non-Aboriginal women and by $2 \%$ per year for Aboriginal women. To achieve these targets, the New South Wales Ministry of Health is currently implementing Quit for New Life, a program facilitating improved provision of smoking cessation support to pregnant Aboriginal women. The impact of this program will be assessed and reported.

The observed associations between demographic characteristics and smoking cessation may in part reflect differential access to smoking cessation support. To the authors' knowledge there are no Australian studies exploring factors associated with access to smoking cessation support during pregnancy, however overseas evidence suggests smoking cessation support is less likely to be provided to older women and poorer women [28]. In addition, there is evidence access to smoking cessation support varies by ethnicity, with one American study of pregnant women finding African American women were more likely, and Native American women less likely, to report receiving smoking cessation support compared to other women [29]. Several studies have also explored whether the effectiveness of smoking cessation support during pregnancy varies by demographic characteristics, however evidence is mixed. A recent systematic review concluded that psychosocial smoking cessation interventions during pregnancy are effective in reducing smoking in pregnancy. Sub-group analyses indicated psychosocial interventions have similar effectiveness among women from lower socioeconomic groups compared to other women, however trials in specific ethnic groups (African-American and Hispanic women) and Aboriginal women have found no treatment effect [30].

The main limitations of this study relate to the use of administrative data. First, the self-reported smoking status recorded in this dataset has not been validated. Self-reported data may underestimate the true rates of smoking in pregnancy as some women may choose not to disclose their smoking status, or unsuccessful attempts to stop smoking, to a health care provider. Second, the administrative dataset used for this analysis contains very limited information about smoking cessation. Using the available data, smoking cessation is defined as smoking during the first half of pregnancy but not in the second half. Smoking cessation which occurs during the second half of pregnancy is not recorded, as women who smoke at any time during the second half of pregnancy are recorded as smokers. Therefore it is likely that the Perinatal Data Collection underestimates rates of smoking cessation during late pregnancy. Further research is required to develop and validate robust measures of smoking cessation that could be incorporated into routine maternity data collection processes.

\section{Conclusions}

Between 2000 and 2011, rates of smoking cessation during pregnancy improved dramatically across all demographic groups, particularly after 2007. However, specific demographic groups remain significantly less likely to quit smoking during pregnancy, including teenage mothers, women living outside major cities, Aboriginal women, and women with higher numbers of previous pregnancies. The findings suggest a need for targeted efforts to promote smoking cessation in specific population subgroups.

Competing interests

The authors declare that they have no competing interests.

\section{Authors' contributions}

EP contributed to the interpretation of the data and prepared the manuscript. RM participated in the design of the study, performed the statistical analysis and helped to prepare the manuscript. PC contributed to the interpretation of the data and preparation of the manuscript. JB conceived the study question, participated in the design of the study, provided advice on statistical analysis, and contributed to the interpretation of the data. All authors read and approved the final manuscript.

\section{Acknowledgements}

This manuscript was written while the authors were employed by the NSW Ministry of Health. The authors designed the study, conducted data analysis and interpretation and prepared the manuscript. The final manuscript was approved by the NSW Ministry of Health.

Received: 30 June 2014 Accepted: 31 March 2015

Published online: 18 April 2015

\section{References}

1. US Department of Health and Human Services: The Health Consequences of Smoking - 50 Years of Progress: A Report of the Surgeon General. Atlanta: US Department of Health and Human Services, Centers for Disease Control and Prevention, National Center for Chronic Disease Prevention and Health Promotion, Office on Smoking and Health; 2014.

2. Augood C, Duckitt K, Templeton AA. Smoking and female infertility: a systematic review and meta-analysis. Hum Reprod. 1998;13:1532-9.

3. Waylen AL, Metwally M, Jones GL, Wilkinson AJ, Ledger WL. Effects of cigarette smoking upon clinical outcomes of assisted reproduction: a meta-analysis. Hum Reprod Update. 2009;15:31-44. 
4. Rogers JM. Tobacco and pregnancy. Reprod Toxicol. 2009;28:152-60.

5. Hackshaw A, Rodeck C, Boniface S. Maternal smoking in pregnancy and birth defects: a systematic review based on 173687 malformed cases and 11.7 million controls. Hum Reprod Update. 2011;17:589-604

6. Zhang K, Wang X. Maternal smoking and increased risk of sudden infant death syndrome: a meta-analysis. Leg Med (Tokyo). 2013;15:115-21.

7. Ayer JG, Belousova E, Harmer JA, David C, Marks GB, Celermajer DS. Maternal cigarette smoking is associated with reduced high-density lipoprotein cholesterol in healthy 8-year-old children. Eur Heart J. 2011;32:2446-53.

8. Carlsen KH, Carlsen KC. Respiratory effects of tobacco smoking on infants and young children. Paediatr Respir Rev. 2008;9:11-9.

9. Clifford A, Lang L, Chen R. Effects of maternal cigarette smoking during pregnancy on cognitive parameters of children and young adults: a literature review. Neurotoxicol Teratol. 2012;34:560-70.

10. Button TM, Thapar A, McGuffin P. Relationship between antisocial behaviour, attention-deficit hyperactivity disorder and maternal prenatal smoking. Br J Psychiatry. 2005;187:155-60.

11. Ekblad M, Gissler M, Lehtonen L, Korkeila J. Prenatal smoking exposure and the risk of psychiatric morbidity into young adulthood. Arch Gen Psychiatry. 2010;67:841-9.

12. Laws PJ, Sullivan EA. Australia's mothers and babies 2001. AlHW Cat. No. PER 25. Australian Institute of Health and Welfare National Perinatal Statistics Unit: Sydney; 2004

13. Li Z, Zeki R, Hilder L, Sullivan EA. Australia's mothers and babies 2011. AlHW Cat. No. PER 59. Canberra: Australian Institute of Health and Welfare National Perinatal Epidemiology and Statistics Unit; 2013.

14. Mohsin M, Bauman A, Forero R. Socioeconomic correlates and trends in smoking in pregnancy in New South Wales, Australia. J Epidemiol Commun H. 2011;65:727-32.

15. Laws P, Li Z, Sullivan E. Australia's mothers and babies 2008. AlHW Cat. No. PER 50. Sydney: Australian Institute of Health and Welfare National Perinatal Statistics Unit; 2010.

16. Giglia RC, Binns CW, Helman SA. Which women stop smoking during pregnancy and the effect on breastfeeding duration. BMC Public Health. 2006;6:195.

17. Mohsin M, Bauman AE. Socio-demographic factors associated with smoking and smoking cessation among 426,344 pregnant women in New South Wales, Australia. BMC Public Health. 2005;5:138.

18. Lu Y, Tong S, Oldenburg B. Determinants of smoking cessation during and after pregnancy. Health Promot Int. 2001;16:355-65.

19. Lumley J, Chamberlain C, Dowswell T, Oliver S, Oakley L, Watson L. Interventions for promoting smoking cessation during pregnancy. Cochrane Database Syst Rev. 2009;3, CD001055.

20. Bedford K, Wallace C, Carroll T, Rissel C. Pregnant smokers are receptive to smoking cessation advice and use of nicotine replacement therapy. Aust N Z J Obstet Gynaecol. 2008;48:424-6.

21. McCurry N, Thompson KA, Parahoo K, O'Doherty E, Doherty A-M. Pregnant women's perception of the implementation of smoking cessation advice. Health Educ J. 2002;61:20-31.

22. McLeod D, Benn C, Pullon S, Viccars A, White S, Cookson T, et al. The midwife's role in facilitating smoking behaviour change during pregnancy. Midwifery. 2003;19:285-97.

23. Australian Bureau of Statistics: 1259.0.30.004 - Australian Standard Geographical Classification (ASGC) Remoteness Structure (RA) Digital Boundaries, Australia, 2006. [http://www.abs.gov.au/AUSSTATS/abs@.nsf/0/0D204FD3DCD90564C A256F19001303A2?opendocument]

24. Australian Bureau of Statistics: 2039.0 - Information Paper: An Introduction to Socio-Economic Indexes for Areas (SEIFA), 2006. [http://www.abs.gov.au/ ausstats/abs@.nsf/mf/2039.0/]

25. Australian Government Preventative Health Taskforce: Australia: the healthiest country by 2020, Technical Report No 2. Tobacco control in Australia: making smoking history. Canberra: Commonwealth of Australia; 2009.

26. Scollo MM, Winstanley MH. Tobacco in Australia: Facts and issues. 4th ed. Melbourne: Cancer Council Victoria; 2012.

27. NSW Department of Premier and Cabinet. NSW 2021: A plan to make NSW number one. Sydney: NSW Department of Premier and Cabinet; 2013

28. Kogan MD, Kotelchuck M, Alexander GR, Johnson WE. Racial disparities in reported prenatal care advice from health care providers. Am J Public Health. 1994:84:82-8.
29. Tran ST, Rosenberg KD, Carlson NE. Racial/ethnic disparities in the receipt of smoking cessation interventions during prenatal care. Matern Child Health J. 2010;14:901-9.

30. Chamberlain C, O'Mara-Eves A, Oliver S, Caird JR, Perlen SM, Eades SJ, et al. Psychosocial interventions for supporting women to stop smoking in pregnancy. Cochrane Database Syst Rev. 2013;10:CD001055.

\section{Submit your next manuscript to BioMed Central and take full advantage of:}

- Convenient online submission

- Thorough peer review

- No space constraints or color figure charges

- Immediate publication on acceptance

- Inclusion in PubMed, CAS, Scopus and Google Scholar

- Research which is freely available for redistribution 